\title{
A CIDADE SEM INFÂNCIA NO UNIVERSO PIONEIRO DA SOJA
}

\section{Odette Carvalho de Lima Seabra* Sérgio Manuel Merêncio Martins ${ }^{\star \star}$}

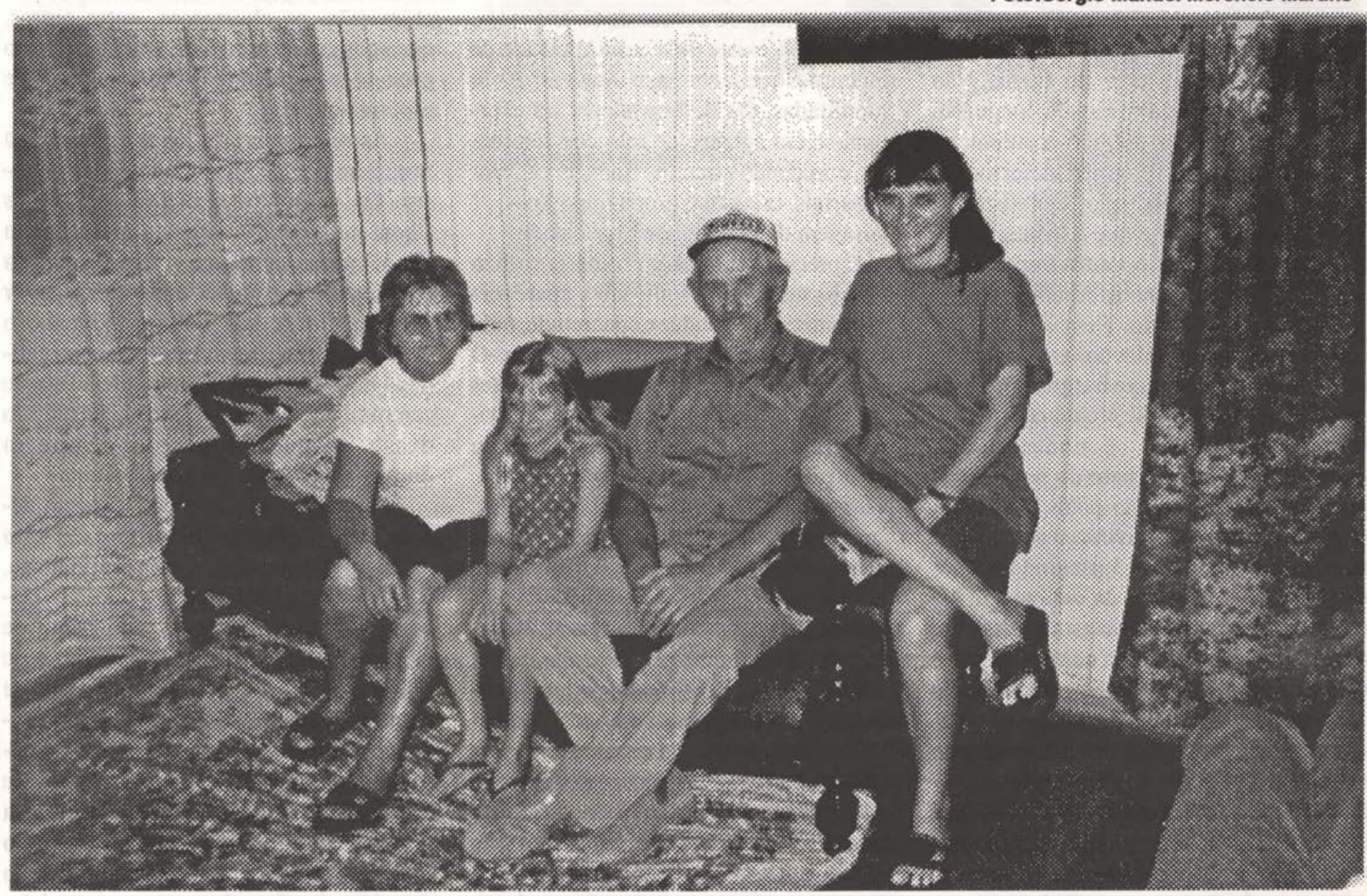

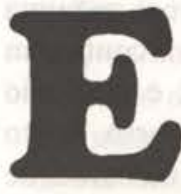

ste ensaio reporta-se a uma cidade formada em área de recente expansão da soja. Cidade sem infância, ou, o que equivale dizer, cidade que nasce adulta, porque inscrita na lógica reprodutiva do capital financeiro internacional. Trata-se do núcleo urbano de Chapadão do Sul, no estado doMato Grosso do Sul, cuja ocupação, a partir do início dos anos 70, é vivida por um movimento pioneiro de gaúchos, oriundos principalmente de municípios como Ijui, Erechim, Palmeira das Missões, Santo Augusto, entre outros. Familias inteiras, grande parte delas de extração rural, lançaram-se a esta terra de horizontes desmesurados e nela implantaram um mundo febril. Estes pioneiros se autodescrevem como desbravadores... e de fato o são.

Como força avassaladora que é, o movimento pioneiro impõe, no lugar, uma lógica nova, e é o inusitado, o bizarro, que constituem os elementos primários para pensar esta cidade adulta, nascida sob os signos do banco, do avião e do trator, encontrando paralelo em muitos outros municípios brasileiros, como no norte do Mato Grosso, e no oeste da Bahia, que se constituem também em áreas recentes de expansão das lavouras tecnificadas de soja. Elas expressam a concretização de estratégias do Estado no sentido da ocupação e colonização de parcelas significativas do território brasileiro, mormente do CentroOeste, no interior de um movimento que desloca de pequenos produtores rurais a grandes empresas para a consecução de monoculturas desenvolvidas em moldes empresariais, contempladas na formulação dos planos e programas que visam, entre outros aspectos, a elevação das exportações brasileiras.

Contudo, nas franjas destas áreas de agricultura modernizada, onde as grandes lavouras de soja assumem posição arquetípica, a cidade é fruto de uma intencionalidade pressuposta. De uma razão que inclui o banco, para financiamentos, pois é através deles que as políticas agricolas se aplicam; o avião, para permitir velocidade aos negócios; e as pesadas máquinas agrícolas, de porte nada desprezível, como tratores e colheitadeiras, que 
atestam o patamar tecnológico das lavouras. Não faltam, pois, elementos de modernidade neste universo, que se manifestam, num primeiro plano, como empreendimentos econômicos.

Na verdade, o singular deste movimento migratório é a redefinição que implica aos sujeitos no seu decorrer. Este espaço estratégico, produto de "télescopage", nos termos de Henri Lefebvre(1), impôs-se sobre realidades precedentes, fazendo tábula rasa da história do lugar. Não obstante, esta prática doEstado, longe está de subverter a ordem político-econômica e lógica da inserção da propriedade territorial nos marcos da reprodução capitalista.

Por conta disto, é que o avião, com o especulador fundiário, vem à frente, antecedendo a estrada, estabelecendo as regras do mercado fundiário. Nessas áreas, tão importantequanto as lavouras modernizadas são os negócios com as terras. Os seus agentes se impõem e se reconhecem como portadores da modernidade, consequentemente, a base do poder local encontra-se estruturada pelos nexos que ligam a propriedade territorial à sociedade que ai se estabelece, instalando-se nos mais diminutos liames da vida social. No cume, está o proprietário estrategista, "o dono", aquele que tinha conhecimento e informação e os aplicou no entendimento das politicas do Estado devotadas ao espaço, no caso, à ocupação de Chapadão do Sul.

Neste universo a ocupação é mediada e determinada pela propriedade capitalista do território. Nele somente encontram sentido as relações que se conformam no âmbito dos padrões definidos desta forma de sociedade, na qual se tem reservado um lugar estratégico à propriedade territorial, para viabilizar formas rentistas de acumulação. Em verdade, o capitalismo no Brasil reproduz-se parcamente, definindo-se como rentista e inacabado(2).

As relações que se estabelecem com e pelos pioneiros, além de porem em xeque sentidos concernentes a terra derivados de concepções de mundo diferentes, têm como elemento fundante e visceral as mediações necessárias aos requisitos atuais da reprodução social - como, por exemplo, o banco -, e que até então se faziam ausentes. Na realidade pioneira só é concebível como modo de existência possivel o que está condicionado a um mundo "sem peias", em que pesem suas contradições. A lógica da reprodução neste universo é já uma lógica de tempo, implicando uma atualização com redefinição da vida social. A rigor, as novas técnicas produtivas são acompanhadas de relações, comportamentos, valores novos, que, ao se imporem, antagonizam-se e consagram à obsolescência oque se encontra dissonante com os atributos e o ritmo do ciclo da soja. Portanto, se existe uma multiplicidade de dimensões que se abrem, muitas outras são interditadas. Os desbravadores transformam-se em agentes de relações complexas, enredando circuitos financeiros, empresariais, criando e produzindo uma paisagem de grande homogeneidade.

É preciso ver também como se realiza a forma urbana, pois ali, sob a aparência emblemática de solidez e concretude, tudo se move irriquieta e incessantemente. $\mathrm{O}$ transitórioe oefêmero sãotraços marcantes do mundo pioneiro. Nenhum entendimento clássico sobre a cidade conduz ao seu esclarecimento. A centralidade é difusa. Nem mesmo o banco, centro de negócios, consegue estabelecê-la. O elemento da forma urbana mais esclarecedoré, ao mesmo tempo, o mais irrisório: a estrada, por onde se chega, e por onde se parte. Numa frente pioneira, muitos "caminham para diante", como já observara, com propriedade, Léo Waibel(3).

Nestas condições, a cidade ganha forma derivada de uma concepção de espaço cujo conteúdo se sustenta na apropriação e valorização do território, objeto de esquadrinhamento que expressa um urbanismo promíscuo, carente de qualquer princípio, e com uma regularidade restrita ao tamanho dos lotes; uma estética sem magnificiência, sem monumentalidade, sem espaços públicos. As ruas, largas, não pertencem as casas. São de domínio das caminhonetes, dos automóveis,... A natureza das edificações espelha uma segregação imanente, sendo também reveladora de elementos de cultura ali revividos, observáveis nos belos jardins das casas dos velhos pioneiros, por exemplo.

Nos interstícios da rispidez das formas da cidade também estão contidos elementos identitários que buscam realizar algum nível de imediaticidade das relações. O Centro de Tradições Gaúchas, e o Centro Ecumênico, ambos revelam as fragmentações, separações e, ainda que precaria- mente, algumas redefinições da base cultural.

Na perspectiva dos citadinos, os elementos da cultura e do cotidiano parecem ser vividos como transposição que a migração, no interior do movimento pioneiro, não conseguiu abalar. Mas há uma descontextualização dos elementos da cultura, como o jogo da bocha, as rodas de chimarrão, os churrascos, entre outros, que agora se inserem no ritmo do ciclo do produto, e, como tal, expressam perda de espontaneidade.

As referências de lugar e de espaço traduzem perspectivas e conteúdos diversos. Os migrantes pioneiros, mesmo os "bem sucedidos", aqueles que "deram certo" como pioneiros, vivem o sonho da conquista, e isto parece constituir o maior fundamento de sua cultura. Vivendo o presente como transitório, vivem a realidade de conquistados, pois, não obstante serem sujeitos, lhes escapa o objeto que são desse mesmo processo. Sonham diuturnamente em "ir para a frente".

Por outro lado, os que "chegam depois' do turbilhão pioneiro, sem dinheiro suficiente para comprar uma propriedade, à procura de onde trabalhar, parecem elaborar a noção de lugar como ponto de chegada, onde procuram se fixar e se reproduzir. E é também na apreciação de como vivem estes migrantes que se evidenciam os processos de segregação contidos nas relações estabelecidas. Por eles e através deles a cidade sem infância ganha quarteirõese quarteirões de autoconstrução precária e improvisada. Reconhecida como deterioração da paisagem, mas também como necessária, na medida em que uma economia propriamente urbana conta com a presença de despossuidos, e estes são essenciais aos processos em curso. $\mathrm{E}$ isto aparece na conformação da mentalidade urbana. A pujança, em qualquer circunstância, carrega o seu contrário.

Nestas condições, a cidade se justifica antes de tudo pelos circuitos monetários que a envolvem, e, em Chapadão do Sul, essencialmente, pelas condições concebidas como elos de relações necessárias para investimentos. Por isso, o banco lhe é um fator genético. O desenvolvimento das lavouras pressupunha atividades que a elas estão imbricadas direta e indiretamente, como a instalação e ampliação das estruturas armazenadoras dos grãos pro- 
duzidos; o redimensionamento e proliferação de estabelecimentos voltados à comercialização de máquinas e insumos; 0 surgimento de empresas especializadas em planejamento agrícola; a implantação de indústrias cujas matérias-primas são os produtos da terra trabalhada em moldes modernos; os serviços dos caminhões que trazem os grãos das lavouras até as empresas; as agências bancárias que são tomadas de intensa agitação quando são liberados osvultosos recursos financeiros necessários a tão grande empresa,... Enfim, pode-se dizer que estas atividades enredadas à égide do cultivo de soja, têm as porções lindeiras da auto-estrada como localizações mais propícias para a implantação dos estabelecimentos, devido à acessibilidade garantida. Como decorrência, também ganham visibilidade os processos instaurados, podendo, num certo sentido, serem lidos como atestados de riqueza e dinamismo.

No entanto, a forma de uso do espaço da cidade realiza e confirma a lógica do especulador, que consiste em extrair a máxima renda dos atributos diferenciados de cada localização intra-urbana.

Mas na medida e porque a cidade se justifica mais pelos circuitos monetários que a envolve, estão ai negados os elementos mais significativos da vida urbana: a pontencialização das capacidades individuais, e o poder socializante da cidade como virtualidade. Por isso, o cotidiano, sem deixar de ser mediação, autonomizase na sua banalidade, um dia atrás do

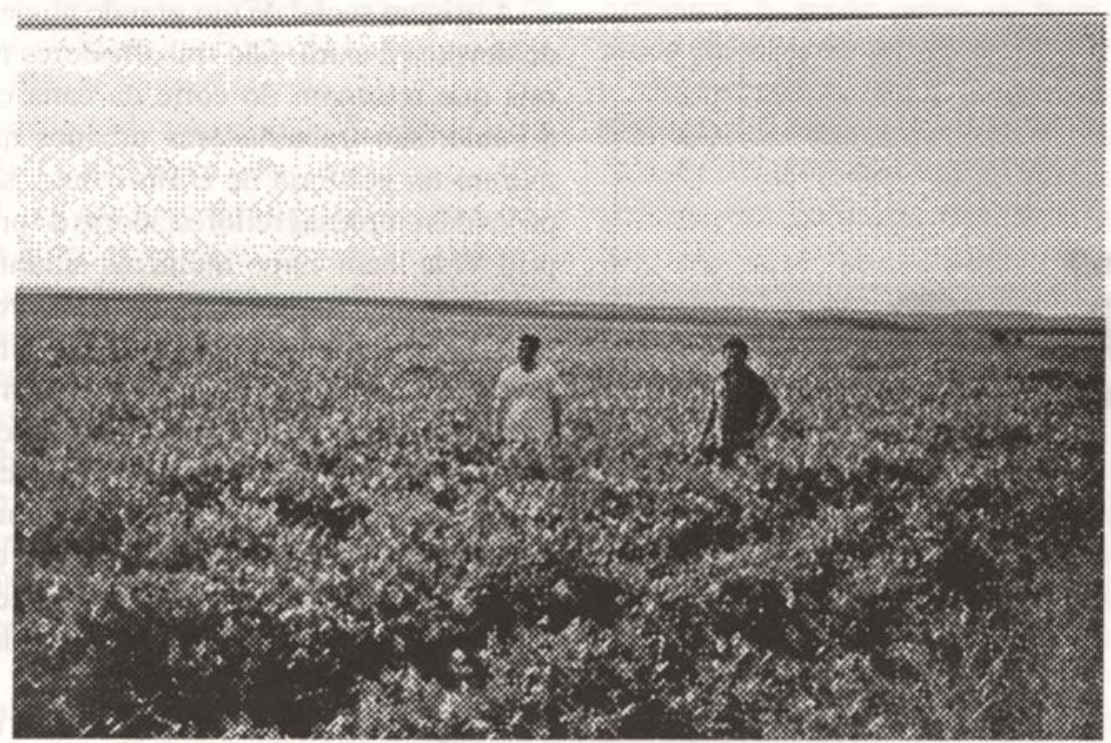

Foto:Sérgio Manuel Merêncio Martins como projeto e prática da produção do espaço estatista, está nele, como possibilidade, mas sobretudo fora dele, como realidade e prática. Está nos retornados, pois nem todos realizam-se como pioneiros, e aqueles que voltam já não são o que foram, como também está no enorme contingente de população deslocada, empurrada para outras áreas, cidades "velhas", no caso que se estuda: Cuiabá, Coxim, Campo Grande. Nestas cidades também está o outro lado do mundo da soja, manifestando-se na sua periferização descomunal. A recente periferia de Coxim, por exemplo, ironicamente denominada "o grilo", é hoje pelo menos três vezes maior que a antiga cidade.

Estas reflexões sobre o movimento pioneiro sugerem pensar no que os gaúchos deixaram para trás. E, nesse sentido, ainda que as estatísticas possam revelar uma queda do contingente populacional da região, não é possível entender este processo como esvaziamento de território, pois o que ficou naquela região é um território pleno, onde tem lugar concentração da propriedade, redefinição dos usos das terras, com expansão das lavouras modernizadas, ...

A cidade sem infância nasce no mar de soja como lógica de intervenção do Estado no sentido da ocupação e valorização do território nacional. Adulta, porque é produto e consumação estratégica de adequação do espaço e do tempo da mụndialidade. Lemos as metrópoles como cidades mundiais, com base em inúmeras evidências empíricas, mas como não conceber a cidade sem infância também como manifestação empírica dessa mesma mundialidade?

- Odette C. de Lima Seabra é professora do Dpto. de Geografia da Universidade de Săo Paulo.

** Sérgio M.M. Martins é mestrando em Geografia Humana pelo Dpto. de Geografia da Universidade de Săo Paulo.

\section{NOTAS}

1) LEFEBVRE, Henri. De I'Etat, Union Générale I'Editions, vol. 4, Paris, 1977.

2) Cf. MARTINS, José de Souza. Caminhada nq Chão da Noite, Hucitec, São Paulo, 1989.

3) WAIBEL, Léo. Capitulos de Geografia Tropical to Brasil, IBGE, Rio de Janeiro, 1979. 